\title{
Considering the cultural context in psychopathology formulations
}

\author{
J Hassim, C Wagner \\ Department of Psychiatry, School of Medicine, University of Pretoria, Weskoppies Hospital, Pretoria, South Africa \\ J Hassim, PhD (Psychology)
}

Department of Psychology, Faculty of Humanities, Hatfield Campus, University of Pretoria, South Africa

C Wagner, D Phil (Psychology)

Corresponding author: J Hassim (junaidh@telkomsa.net)

Background. Mental health research appears to be continually transforming. Recent literature reflects a greater appreciation for the ways in which pathoplastic features of culture modulate emotional regulation. This article introduces those aspects of the literature which explore the (re)consideration of culture as a dynamic and essential construct in the clinical formulation of psychopathology.

Objectives. The study aims to review literature that focuses on the dynamic influence of culture in psychopathology. Furthermore, the researchers aim to present a view on the ways in which culture appeared to shape the topography of psychopathology nosology.

Method. A literature review of 31 sources.

Results. The review indicated that 29 literature sources were conceptual in design, suggesting a great need for more empirical research. This section also explores themes identified during the literature review. The literature is tabulated according to features and emerging themes. Three major themes were identified and included: the cultural context; the evolving definitions of culture; and culture and psychopathology. Conclusion/discussion. An analysis of the themes is offered. The authors conclude by highlighting the significance of the literature at present. Areas of particular interest suggest that health and behaviour are dependent, at least in part, on culture; psychopathology may also be appreciated as a social construct; culture influences psychopathology regardless of the aetiology; diagnostic classes do not adequately consider operational definitions; and a greater focus on hermeneutic perceptivity in appreciating cultural dynamics in psychopathology will benefit clinical assessment.

S Afr J Psych 2013;19(1):4-10. DOI: 10.7196/SAJP.400

It has become apparent that psychiatric patients yearn for more than a diagnosis: they have a great need to appreciate their experiences from a cultural and social perspective. ${ }^{[1]}$ Culture influences views and experiences during the course of one's life, which then have an influence on behaviour. Thus, persons of different cultures may articulate similar behavioural tendencies, but express them according to culturally sanctioned norms. ${ }^{[2]}$

Of significance is a culture's capacity to modulate emotional regulation. ${ }^{[3]}$ In traditional African cosmology, for example, the symbiosis between the seen and unseen is unquestionably acknowledged. ${ }^{[4]}$ Numerous theories focused on the composition of emotion do not illustrate the African experience effectively. ${ }^{[5]}$ To illustrate such experiences, there appears to be a need for thorough assessment of cultural views on psychopathology. However, the need to explore cultural conceptualisations of psychopathology is not new. Edgerton ${ }^{[6]}$ researched psychopathology in the traditional African domain and requested that research explore the cultural domain so in order to inform academia. Edgerton's primary concern was that modern nosologies misrepresent the cultural and social veracity of authentic cultural experience. To reframe these views, it appears that, in some clinical contexts, a culture of misunderstanding psychopathology has been observed.

In many ways cultures, relative to epochs and geographical contexts, determined the development of present-day psychopathology formulation. As such, the understanding of psychopathological symptoms has varied from place to place, time to time, and community to community. None of the formulations, however, appear to have received as much academic interest as the Western view of mental illness. Bhugra and Bhui ${ }^{[7]}$ hold that the misdiagnoses of what they describe as Western-specific psychopathology may occur due to limited cultural awareness. This is particularly evident if one considers the body of knowledge signifying, for example, that auditory hallucinations are dependent on the pathoplastic influences of culture - that is, the ways in which psychological distress manifests. ${ }^{[7]}$

Certainly, research into culture will help clinical formulation develop towards a more holistic approach. While there is currently an emphasis 
on a biopsychosocial model of psychopathology, this ought to become more holistic and therefore biopsycho-sociocultural. ${ }^{[8]}$ According to Miller ${ }^{[9]}$ the acknowledgement of culture is important to most applicable frameworks, irrespective of the discipline or paradigm. Furthermore, the view that diagnoses and experiences are constant within cultures is reasonably imprecise, as constant taxonomies and definitions of psychopathologies suggest an ideal, not realistic, state. ${ }^{[10]}$ How, then, does one operationalise culture and psychopathology as constructs?

Culture is a quality which is environmentally acquired, and should be viewed as containing beliefs, principles, standards, activities, and symbols. ${ }^{[3]}$ It reflects mutual societal experiences, is conveyed cross-generationally, and transforms in due course. Culture is also self-sufficient, and consists of concrete and abstract components. Furthermore, a population's survival and acclimatisation are dependent on culture. Many aspects of culture, such as cultural principles, affect the manner in which people perceive and react. ${ }^{[3]}$ Further, Reber and Reber ${ }^{[11]}$ define psychopathology as the investigation of mental illness or anguish, or signs of behaviours and occurrences which may denote mental illness or psychological wounding. Hence, the terms psychopathology and serious psychological distress may be used interchangeably.

\section{Objective}

According to Wohl, ${ }^{[12]}$ researchers and clinicians alike contend that therapists who work with patients from various cultures must aim to attain as much knowledge about a culture as possible, so as to develop insight into a patient's cultural influences. The time is ripe for academia and clinicians to focus more on culture-fit care. ${ }^{[13]}$ Canino and Algería ${ }^{[15]}$ implore mental health professionals to integrate culture more frequently into their clinical formulations. This study aims to attend to these recommendations by reviewing literature focused on the dynamic interplay of culture and psychopathology, as well as culture in psychopathology.

We ask: In which ways does the literature indicate a need for culture to be incorporated into the applied utility of psychopathology formulation?

\section{Method}

Constructive research will weave multiple studies together, giving clinicians the chance to gain a comprehensive appreciation of culture and psychological distress. ${ }^{[16]}$ Draguns and Tanaka-Matsumi ${ }^{[17]}$ recommend that research should focus on linking discrete studies, in a way that makes greater understanding of psychological dynamics available to academia. It appears that a literature review will fulfill this requirement, ${ }^{[18]}$ and this was the method selected for this study, based on the observation that studies regarding psychopathology are often dispersed and divided. ${ }^{[17,19]}$ This investigation therefore endeavours to assimilate discrete studies, and to emphasise the significance of considering cultural aspects in the understanding of psychopathology. The specific method of literature review used was research synthesis, ${ }^{[20,21]}$ which entails outlining and integrating research $^{[22,23]}$ in order to augment practice and policy. ${ }^{[24]}$

\section{Criteria for eligibility of literature}

Inclusion criteria included:

- Published (formal) studies from 1980 onwards - this accounts for an increase in published literature since 1985, observed during the preliminary review.

- Studies that predate 1980 were included if they were justifiably, if not overtly, relevant; this practice is acceptable according to Higgins and Green. ${ }^{[25]}$

- Literature which promoted new understanding with regard to culture as a construct in the clinical context

- Studies relating to psychopathology in terms of: diversity; subjectivity; and a bio-psycho-social appreciation.

\section{Exclusion criteria include:}

- Informal (that is, unpublished) literature

- Studies which were older than 30 years unless they were justifiably relevant.

The literature search terms included the following terms, both separately and in combination: culture, psychopathology, psychiatry, psychology, worldview, and epistemology. The databases consulted included major search facilities such as GoogleScholar, JSTOR and EBSCOHOST.

\section{Results}

Table 1 summarises the data accrued during the literature review. A total of 31 literature sources met the inclusion criteria. Of these, 3 were empirical and 29 were conceptual in design. This suggests a need for more empirical research to be conducted in this domain. Note that the resourced literature was available in the public domain and freely available to academic staff and students at the University of Pretoria. Other references could not be accessed due to the limited resources available to the authors.

In the present review, 3 themes were identified in the literature. These included: the cultural context; the evolving definitions of culture; and culture and psychopathology. These are discussed in detail hereafter.

\section{Theme 1: The cultural context}

People ardently defend their cultural worldviews. ${ }^{[26]}$ This is understandable as worldview defines their conception of the nature of reality and all epistemological notions thereof. Indeed, culture and religion define the acceptability of affect, cognition, and connation. Suicidal behaviours are a good example: ${ }^{[27]}$ a common Muslim view is that suicide is forbidden in Islam, but in certain Japanese communities it may be seen as honourable.

If the clinician's erudition in the patient's culture logically suggests cultural competency, then it may be hypothesised that potential benefits result from this competency. These may include the supplication of culturally sensitive treatment, and may also foster the establishment of rapport in clinical interactions. ${ }^{[28]}$

There appears to be an increase in the body of literature regarding ethnic, racial, and cultural perceptions, ${ }^{[29-31]}$ which in turn seems to 


\section{ARTICLE}
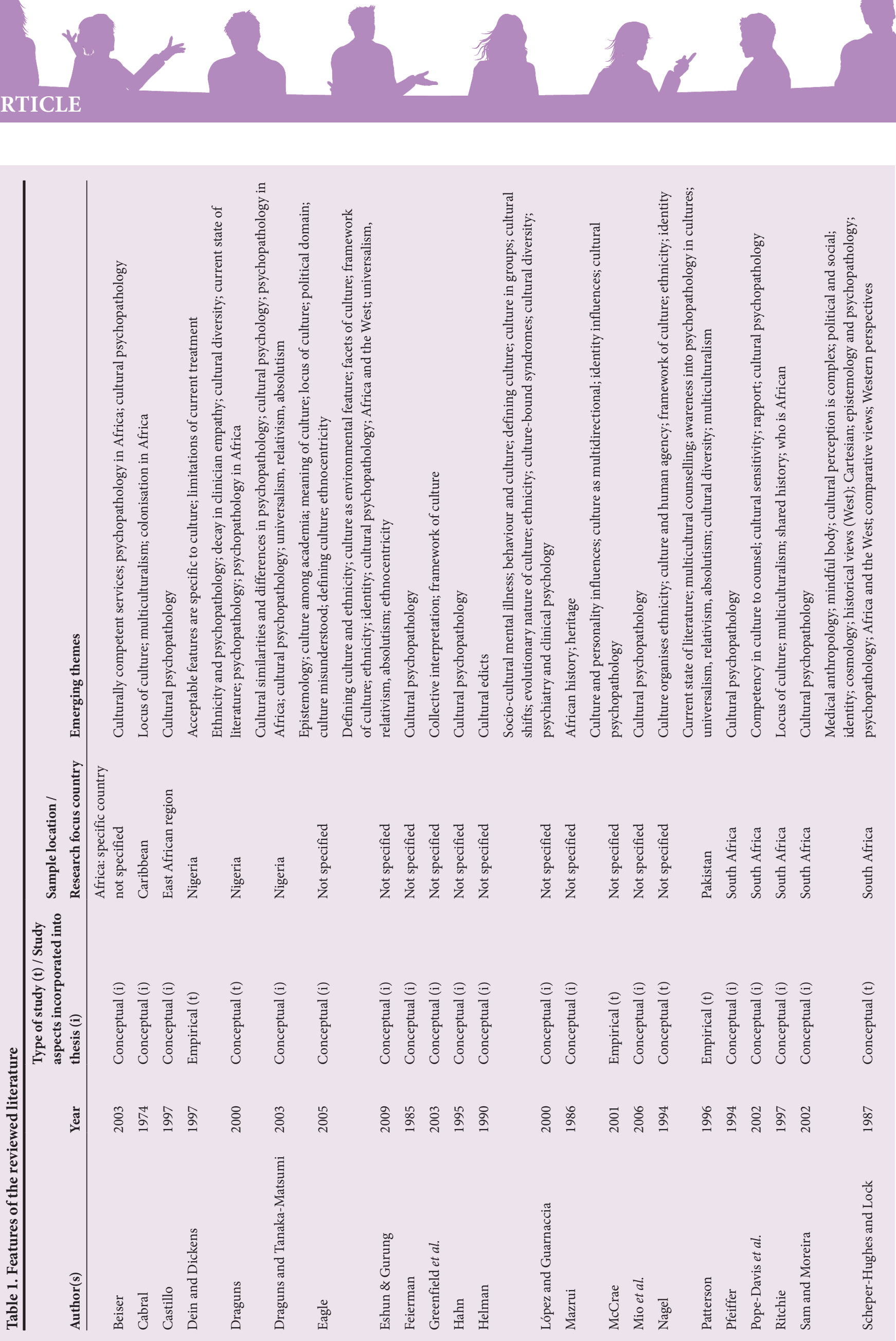


\section{Ary S 2 $A$ res $\beta$

focus on increasing awareness of various perspectives on psychological distress. ${ }^{[30]}$ As a result, recent research has attempted to explore what culture means in clinical psychology. ${ }^{[26]}$

Eagle $^{[26]}$ claims that the term culture possesses significant rhetorical energy. As such, culture creates a context whereby psychopathology has meaning, and assists in developing theories about psychopathology. Furthermore, understanding culture allows professionals to appreciate the human condition in such a way that they may provide services that are culturally competent. ${ }^{[32]}$ Unfortunately, the terms 'culture', 'race', and 'ethnicity' have been applied with confused utility, and this has been a noteworthy hurdle in the development of cultural psychology. ${ }^{[8]}$

Culture is associated with ethnicity and one may contend that culture and ethnicity intermingle, but they are not the same. ${ }^{[33]}$ Some individuals misuse the term 'culture' to represent ethnicity, race, and/or culture. ${ }^{[3]}$ It appears that these terms are often, and incorrectly, used interchangeably. The obvious question here is: What is culture? Considering the evolving definitions of culture may assist in this regard.

\section{Theme 2: The evolving definitions of culture}

It is important to consider a relatively aged piece of the literature at this juncture, as much of it still relates to the present definitions of culture. In line with White's ${ }^{[34]}$ reasoning, some have defined culture as conditioned behaviours, while others appear to define culture as an abstraction underlying behaviour. While material objects may be perceived as embodying culture, culture is not dependent on material objects. Often, culture appears to relate to objects and behaviours which are perceptible, but it is equally fair to state that culture exists in the mind. Culture's vast possibilities are so intricate and complex, and its conceptions of energy so diverse, that physics would probably become convoluted if it were able to encompass culture's verve. ${ }^{[34]}$

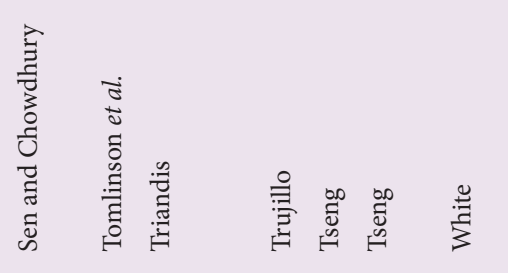

Considering White's ${ }^{[34]}$ definition, there is little doubt that defining culture is difficult. The body is a cultural and physical object. Attempting to define the end of physical matter complex. ${ }^{[35]}$ The difficulties are compounded because many definitions of culture appear to suggest that it exists within a person. ${ }^{[16]}$

As a collection of edicts, passed from community to individual, culture defines the community's worldview, the nature of interpersonal relationships within it, and the nature of being. These edicts are diffused through language, customs, art, and symbols. ${ }^{[36]}$ Culture is also a network of dynamic attributes that direct and train perception, reasoning, interaction, and behaviour. ${ }^{[37]}$ Accordingly, culture cannot remain static and is reconstructed according to shifts in these attributes. Culture, therefore, evolves. ${ }^{[16]}$

As a unit of interrelated attitudes, beliefs, ethics, and behavioural perceptions shared by a community and carried down from one generation to the next, culture is a construct that operates at the collective level and does not relate to biological or individual performance. It does, however, reside in the individual's knowledge schema and, while it develops during childhood, it is fortified during the life-cycle. ${ }^{[38]}$ Culture is socially interactional and consists of collective practices and joint interpretations of phenomena. ${ }^{[39]}$

As a result, culture forms collective meaning, and structures communities via folklore and history. Culture therefore creates a foundation for organising ethnicity, but is not ethnicity. Because culture relates to meaning, it influences aspects such as belief systems, traditions and lifeways that represent real ethnicity. While ethnic boundaries signify the structural aspects that influence ethnic opinions, culture signifies human agency and in-group operations of cultural protection, renovation, and advancement. ${ }^{[40]} \mathrm{A}$ superior definition of culture must appreciate the person's agency in creating his/her social world. This suggests that people do not inherit culture from generalised society. While society helps shape cultural perception, so does the individual's life experiences. It is reasonable to appreciate that a person may transform, augment, or discard aspects of culture based on personal perception. ${ }^{[16]}$ and the beginning of cultural perception is

\section{Theme 3: Culture and psychopathology} All cultures experience psychopathology. Pfeiffer's ${ }^{[41]}$ review of anthropological data 
suggests that even individuals from minority cultures are not exempt from experiencing anxiety. Appreciating culture's position in mental health is imperative to thorough and precise diagnoses, as well as the treatment of psychopathology. This is because psychopathology and culture are rooted in one another. ${ }^{[42]}$

The question that needs be clarified when considering culturerelated psychopathology is whether the phenomenon is culturally induced, culturally modified, or culturally labelled. Clearly, these dimensions suggest that some phenomena warrant little psychiatryspecific differentiation. ${ }^{[13]}$ Behavioural scientists without psychiatric knowledge and experience find it complex to appreciate the nature of culture-related psychopathology in a suitable and meaningful way. Culture-related disorders stem from cross-cultural psychopathology, a position which contemporary transcultural psychiatry is attuned to appreciate. ${ }^{[13]}$

Briefly, culture exerts pathogenic, psychoselective, psychoplastic, pathoelaborating, psychofacilitating, and psychoreactive influences. According to Tseng, ${ }^{[13]}$ the pathogenic effect refers to culture's propensity to affect the course of the disorder. We propose that the pathogenic effect be appreciated as the way in which culture habituates psychopathology. The psychoselective effect refers to the way in which cultural variables enable the person to tolerate stressors. Of equal importance is the psychoplastic effect, which elaborates the manner in which culture modulates the expression of psychopathology. Structured manifestation of this modulation, as implied in mainstream categories as well as culture-specific illnesses, suggest culture's pathoelaborating effect. However, as psychopathological experiences often relate to the personalised experience of psychological disturbances, the psychoreactive effect explores the subjective reaction to the disturbance. ${ }^{[14]}$ In various ways, these patterns appear to relate to some of the frameworks appreciated in the clinical context.

Mio, Barker-Hackett, and Tumambing ${ }^{[43]}$ are of the opinion that there are 4 recurring frameworks which address the way in which psychopathology is influenced by culture. These include:

- the sociobiological approach

- the ecocultural approach

- the biopsychosocial approach

- multiculturalism.

From a sociobiological point of view, evolutionary and biological features affect culture, and culture evolves in order to sustain the survival of society. The ecocultural approach focuses on the relationship between ecology and culture, specifically the manner in which actions and opinions affect the environment and vice versa. The biopsychosocial view considers the interaction between biological, psychological, and social factors. This approach interprets the influence of culture on psychopathology through a trimodal framework (bio-psycho-social) and its dynamic interplay on social interaction. Multiculturalism is a postmodernism-endorsed approach and highlights the significance of equity between and approval of all cultural views. Proponents of this approach aim to expand awareness of the dynamics of all cultures, so as to promote positive interaction between all societies. ${ }^{[43]}$

While Draguns and Tanaka-Matsumi ${ }^{[17]}$ demonstrate that culture has a substantial influence on psychopathology, the various facets of culture in producing idiosyncratic symptoms of psychopathology have yet to be discovered. From an etic perspective, prospective researchers may explore collective views regarding antecedents in relation to the emergence of psychopathology. From an emic orientation, nuances may be explored with regard to culturally shared premises and concerns. Draguns and Tanaka-Matsumi request that prospective studies explore the generic association between culture and psychopathology, as well as identifying relationships between psychological distress and cultural features.

Culture affects psychopathology through the patient's subjective experience of the distress. Furthermore, patients exhibit symptoms of distress in accordance with the standards and context defined by their cultures. The expression of the manner in which symptoms are exhibited is then interpreted by a clinician and diagnosed accordingly. Understanding the cultural dynamics at play, with regard to symptom manifestation, determines treatment options and has an influence on prognostic factors. ${ }^{[4]}$ Language is also influenced by culture, thereby influencing the way in which illness is understood. Both the experience of illness and the conceptual understanding of illness depend on language. ${ }^{[45]}$

Every culture possesses personalised knowledge with regard to the perception and interpretation of illness. ${ }^{[4]}$ Although anxiety disorders are prevalent in many cultures, they are expressed differently across cultures; ${ }^{[29]}$ the dissimilarities in psychopathological expressions across diverse cultures are extraordinary. ${ }^{[17]}$ The experience, and interpretation, of hallucinations depends by and large on cultural construal. This is most notably evident in cultural interpretations of hallucinations as either pathological or supernatural. It is therefore of great consequence to appreciate that hallucinations transpire in context, are related to antecedent and consequential events, and only develop into a symptom when they are regarded as such. ${ }^{[17]}$

\section{Discussion}

This section aims to process the results of the literature review. As such, significance of the data is applied using an integrative theoretical perspective.

In terms of cultural constructions, there is little doubt regarding the pivotal role of culture's influence in constructing medicine and healing. [47] Critics of this view have, understandably, been ill-equipped to account for the complex and multifarious dynamics relating to psychotic processes. ${ }^{[50]}$ While biological theory has afforded the clinical domain many insights into healing, proponents' efforts to comprehensively account for psychotic processes have been disappointing thus far. ${ }^{[47,49]}$ 
As a minimum, clinicians ought to acknowledge that health, or lack thereof, is partly dependent on culture. ${ }^{[50]}$ Culture may have a positive, as well as a negative, effect on health. This is especially evident in terms of the ways in which culture influences behaviour. ${ }^{[50]}$ The review suggested culture's influence on behaviour, but also that the dynamics of culture influence the ways in which people behave when they are ill, thereby influencing interpersonal interaction during illness. ${ }^{[51,52]}$ This operation then perturbs the psychopathological experience ${ }^{[53]}$ It is unsurprising, then, that culture influences psychopathology, regardless of the aetiology of the disorder. ${ }^{[13]}$ This appears to be especially significant with regard to the present psychiatric classificatory systems in mainstream clinical practice.

It appears that diagnostic classes fail to consider operational definitions with regard to culture. For this reason, many clinicians have to depend solely on clinical impressions. ${ }^{[54]}$ Often, culturefocused researchers have found that this process led to frequent misdiagnoses. ${ }^{[7]}$ This is particularly evident if considering the body of knowledge signifying, for example, that auditory hallucinations are dependent on the pathoplastic influences of culture. ${ }^{[7]}$

The manifestation of pathology across cultures is diverse. ${ }^{[17]}$ Symptoms, therefore, ought to be largely interpreted within the cultural context. Discounting the correlation between culture and pathology ${ }^{[2]}$ often leads to inaccurate clinical impressions and diagnoses. ${ }^{[8]}$ However, perhaps the culture-pathology association has been overstated at present, with insufficient information relating to the way in which pathology is affected by culture.

The influences of culture suggest that perceptions of normal and abnormal experiences are regulated by culture, modulating intrapsychic conflict and psychological distress. ${ }^{[8]}$ If it is accepted that culture exerts an influence on psychopathology, then the social function of pathology is insinuated. Further elucidation in this regard may be valuable. Summerfield ${ }^{[55]}$ holds that diagnosticians assume the subsistence of mental illness, irrespective of whether it is diagnosed or not. However, psychopathology may be appreciated as a social construct, buttressed by cultural conceptions of personhood. ${ }^{[55]}$ In this regard, cultural influences shape what people deem normal or abnormal, as well as acceptable or unacceptable.

The discussion now appears to be heading towards the social functions of cultural conceptualisations. However, we contend that to mindlessly and exclusively consolidate cultural conceptions with social processes lacks depth in terms of the dynamics relating to issues of the self. Yet, the way in which the self is defined has great significance for the present contention.

Some may take issue regarding assumptions about the aetiology of psychopathology. To address this, and to limit the chance that the discussion will be riddled by covert constructions, note that the integrative and critical frames will inevitably question mainstream interpretations, so as to heighten hermeneutic perceptivity of various dynamics. ${ }^{[56]}$
In essence, then, the literature review considered the present topography of mental health. Of particular interest were the ways in which culture ought to be considered as a basic construct in defining and diagnosing psychopathological phenomena.

Evidently, comprehensive investigation into a patient's complaints both initiates, and accrues, opulent description, and does not necessarily focus specifically on classificatory symptomatology. ${ }^{[31]}$ This enriches clinicians' understanding of the phenomena, as well as meeting the patients' need to appreciate the dynamics of their experiences. In this regard psychiatry's interpretations are debatable, as they rely on a clinician's perception of the distress. It may be argued that underlying philosophical systems justify psychosis in a more comprehensive way than psychiatric conceptualisations, particularly as philosophical systems include moral and political concerns. ${ }^{[1]}$

This is not to imply that psychiatric diagnostic process should be eradicated, but that incorporating philosophical systems into mainstream psychiatric process will probably augment and develop current mainstream diagnostic systems. In addition, the consideration of culture in psychopathology need not be determined on an exclusionary basis, whereby specific populations are viewed as different to others. As the present study suggested, cultural correspondence is a global phenomenon.

The review also compels one to bear in mind that cultural groups are not disconnected, and overlap other cultures. As a matter of fact, individuals from all cultures absorb facets of other cultures into their perception of self. ${ }^{[30]}$ Culture-specific groups may be becoming a rarity. Furthermore, attempting to generate specific theories and techniques to work with each culture and/or subculture would be impossible. ${ }^{[30]}$ In addition, shared histories cultivate a shared culture. ${ }^{[5]}$ This is particularly significant in a continent such as Africa, defined by multicultural influences. The researchers are also cognisant that some of the perspectives presented will have little utility for some modern and/or acculturated populations. Adapting the scope of this study, for future research, may certainly be valuable in this regard. In addition, the taxonomies this investigation alludes to are subject to revision, as culture remains evolutionary in nature.

Declaration. Ethical approval to conduct this study was obtained from the Faculty of Humanities' Research Ethics Committee at the University of Pretoria. The authors are not aware of any conflicts of interests.

\section{References}

1. Thomas P, Bracken P. Critical psychiatry in practice. APT 2004;10:361-370. [http://dx.doi. org/10.1192/apt.10.5.361]

2. McCrae RR. Trait psychology and culture: Exploring intercultural comparisons. J Pers 2001;69(6):819-846.

3. Eshun S, Gurung AR. Introduction to culture and psychopathology. In: Eshun S, Gurung AR, eds. Culture and Mental Health: Sociocultural Influences, Theory, and Practice. New Jersey: Wiley and Sons, 2009:1-17.

4. Chandler R. The concept of the harmony of science and religion in African culture. In: du Toit $\mathrm{CW}$, ed. Faith, Science and African Culture: African Cosmology and Africa's Contribution to Science. Pretoria: Unisa, 1998:10-18.

5. Dzokoto VA, Okazaki S. Happiness in the eye and the heart: Somatic referencing in West African emotion lexica. Journal of Black Psychology 2006;32:17-40. 
6. Edgerton RB. Conceptions of psychosis in four East African societies. American Anthropologist 1966;68(2):408-425.

7. Bhugra D, Bhui K. African-Caribbeans and schizophrenia: Contributing factors. Advances in Psychiatric Treatment 2001;7:288-293. [http://dx.doi.org/10.1192/apt.7.4.283]

8. Trujillo M. Multicultural aspects of mental health. Primary Psychiatry 2008;15(4):65-71,77-84.

9. Miller JG. Cultural psychology: Implications for basic psychological theory. Psychological Science 1999; 10(2):85-91. [http://dx.doi.org/10.1111/1467-9280.00113]

10. World Health Organization. The ICD-10 Classification of Mental and Behavioural Disorders: Clinical Descriptions and Diagnostic Guideline. Geneva: World Health Organisation, 1992.

11. Reber AS, Reber ES. Dictionary of Psychology, 3rd ed. United Kingdom: Penguin, 2001.

12. Wohl J. Psychotherapy and cultural diversity. In: Aponte JF, Wohl J, eds. Psychological Intervention and Cultural diversity, 2nd ed. Massachusetts: Allyn and Bacon, 2000:75-91.

13. Tseng W. From peculiar psychiatric disorders through culture-bound syndromes to culture-related syndromes. Transcult Psychiatry 2006;43(4):554-576. [http://dx.doi. org/10.1177/1363461506070781]

14. Tseng WS. Handbook of Cultural Psychiatry. California: Academic Press, 2001.

15. Canino G, Algería M. Psychiatric diagnosis - is it universal or relative to culture? J Child Psychol Psychiatry. 2008;49(3):237-250. [http://dx.doi.org/10.1111/j.1469-7610.2007.01854.x]

16. López SR, Guarnaccia PJJ. Cultural psychopathology: Uncovering the social world of menta illness. Annu Rev Psychol 2000;51:571-598. [http://dx.doi.org/10.1146/annurev.psych.51.1.571]

17. Draguns JG, Tanaka-Matsumi J. Assessment of psychopathology across and within cultures: Issues and findings. Behav Res Ther. 2003;41(7):755-776.

18. Cooper HM. Synthesising Research: A Guide for Literature Reviews. California: Sage Publications, 1998

19. Dzokoto VA, Adams G. Understanding genital-shrinking epidemics in West Africa: Koro, juju, or mass psychogenic illness? Cult Med Psychiatry 2005;29(1):53-78

20. Gough DA. Systematic research to inform the development of policy and practice in education In: Thomas G, Pring R, eds. Evidence-Based Practice. Buckingham: Open University Press, 2004:21-33.

21. Popay J. Moving beyond floccinaucinihilipilification: Enhancing the utility of systematic reviews. J Clin Epidemiol 2005;58(11):1079-1180. [http://dx.doi.org/10.1016/j.jclinepi.2005.08.004]

22. Oakley A, Gough D, Oliver S, Thomas J. The politics of evidence and methodology: Lessons from the EPPI-Centre. Evidence and Policy 2005;1(1):5-32. [http://dx.doi. org/10.1332/1744264052703168]

23. Sandelowski M, Voils CI, Barroso J. Defining and designing mixed research synthesis studies. Res Sch 2006;13(1):29.

24. Gough D, Elbourne D. Systematic research synthesis to inform policy, practice an democratic debate. Social Policy and Society 2002;1(3):225-236. [http://dx.doi.org/10.1017/ S147474640200307X]

25. Higgins JPT, Green S. Cochrane Handbook for Systematic Reviews of Interventions: Version 5.0.1. United Kingdom: The Cochrane Collaboration, 2008.

26. Eagle G. Cultured clinicians: The rhetoric of cultural and clinical psychology training Psychology in Society 2004;30:1-22

27. Dein S, Dickens H. Cultural aspects of aging and psychopathology. Aging \& Mental Health 1997;1(2):112-120. [http://dx.doi.org/10.1080/13607869757209]

28. Pope-Davis DB, Toporek RL, Ortega-Villalobos L, et al. Client perspectives of multicultura counseling competence: A qualitative examination. The Counseling Psychologis 2002;30(3):355-393. [http://dx.doi.org/10.1177/0011000002303001]

29. Draguns JG. Psychopathology and ethnicity. In: Aponte JF, Wohl J, eds. Psychological Intervention and Cultural Diversity, 2nd ed. Massachusetts: Allyn and Bacon, 2000:40-58.

30. Patterson CH. Multicultural counselling: From diversity to universality. Journal of Counselling and Development 1996;74:227-231.
31. Tomlinson M, Swartz L, Kruger L, Gureje O. Manifestations of affective disturbance in sub Saharan Africa: Key themes. J Affect Disord 2007;102(1-3):191-198. [http://dx.doi.org/10.1016/j. jad.2006.09.029]

32. Beiser M. Culture and psychiatry, or "The tale of the hole and the cheese." Can J Psychiatry 2003;48(3):143-144.

33. Sen P, Chowdhury AN. Culture, ethnicity, and paranoia. Current Psychiatry Reports 2006;8(3):174:178

34. White LA. The concept of culture. American Anthropologist 1959;61(2):227-251. [http://dx.doi org/10.1525/aa.1959.61.2.02a00040]

35. Scheper-Hughes N, Lock MM. The mindful body: A prolegomenon to future work in medical anthropology. Medical Anthropology Quarterly 1987;1(1):6-41. [http://dx.doi.org/10.1525/ maq.1987.1.1.02a00020]

36. Helman C. Culture, Health and Illness. Oxford: Butterworth Haimann, 1990

37. Mazrui AA. The Africans: A Triple Heritage. Boston: Little, Brown, 1986.

38. Triandis HC. Individualism and Collectivism. Colorado: Westview, 1995.

39. Greenfield P, Keller H, Fuligni A, Maynard A. Cultural pathways through universal development Annu Rev Psychol 2003;54:461-490. [http://dx.doi.org/10.1146/annurev.psych.54.101601.145221]

40. Nagel J. Constructing ethnicity: Creating and recreating ethnic identity and culture. Social Problems 1994;41(1):152-176

41. Pfeiffer W. Transcultural Psychiatry: Findings and Problems. 2nd ed. Stuttgart: Thieme, 1994

42. Sam DL, Moreira V. The mutual embeddedness of culture and mental illness. In: Lonner WJ Dinnel DL, Hayes SA, Sattler DN, eds. Outline Reading in Psychology and Culture. Washington: Center for Cross-Cultural Research, 2008:139-175.

43. Mio JS, Barker-Hackett L, Tumambing J. Multicultural Psychology: Understanding our Diverse Communities. Boston: McGraw Hill, 2006.

44. Castillo RJ. Culture and Mental illness. California: ITP, 1997.

45. Hahn RA. Sickness and Healing: An Anthropological Perspective. New York: Yale University Press, 1995.

46. Feierman S. Struggles for control: The social roots of health and healing in modern Africa. Afr Stud $\operatorname{Rev} 1985 ; 28(2-3): 73-147$.

47. Lupton D. Medicine as Culture: Illness, Disease, and the Body in Western Societies. London: Sage, 1994.

48. Sharpley M, Hutchinson G, McKenzie K, Murray RM. Understanding the excess of psychosis among the African-Caribbean population in England. Br J Psychiatry Suppl. 2001;40:s60-68.

49. Szasz T. The Myth of Mental Illness: Foundations of a Theory of Personal Conduct. New York: Hoeber-Harper, 1961

50. Airhihenbuwa CO, DeWitt Webster J. Culture and African contexts of HIV/AIDS prevention, care and support. SAHARA J 2004;1(1):4-13. [http://dx.doi.org/10.1080/17290376.2004.9724822]

51. Brody H. Stories of Sickness. New Haven: Yale University Press, 1987.

52. Pakaslahti A. Dissociative disorder and possession. Cross-cultural comparisons. Paper presented at Andorra 2001 Transcultural Studies Section, Andorra la Vella, 2001.

53. Adams G, Salter PS. Health psychology in African settings: A cultural-psychological analysis. J Health Psychol 2007;12(3):539-551. [http://dx.doi.org/10.1177/1359105307076240]

54. Bird HR. Epidemiology of childhood disorders in a cross-cultural context. J Child Psychol Psychiatry 1996;37(1):35-49.

55. Summerfield D. The invention of post-traumatic stress disorder and the social usefulness of a psychiatric category. BMJ 2001 13;322:95-98.

56. Outhwaite W. Habermas: Key Contemporary Thinkers. 2nd ed. California: Stanford University Press, 2009

57. Ritchie J. Europe and the European dimension in a multicultural context. European Journal of Intercultural Studies 1997;8(3):291-301.[http://dx.doi.org/10.1080/0952391970080307] 